\title{
The pacemaker current $I_{\mathrm{f}}$ in single human atrial myocytes and the effect of $\beta$-adrenoceptor and $\mathrm{A}_{1}$-adenosine receptor stimulation
}

\author{
Francesco Porciatti, *Brigitte Pelzmann, Elisabetta Cerbai, *Peter Schaffer, Roberto Pino, *Eva \\ Bernhart, *Bernd Koidl \& ${ }^{1}$ Alessandro Mugelli
}

Department of Pharmacology, University of Firenze, Italy and *Institute of Medical Physics and Biophysics, University of Graz, Austria

1 We used single human atrial myocytes to study $I_{\mathrm{f}}$ occurrence, properties and pharmacological modulation. Cells were obtained by chunk enzymatic digestion from samples of right atrial appendages of patients undergoing corrective cardiac surgery.

2 Patch-clamped cells in the whole-cell configuration were superfused with a modified Tyrode solution to reduce contamination by interfering currents and to amplify $I_{\mathrm{f}}$. The average cell membrane capacitance was $85.06 \pm 2.41 \mathrm{pF}(n=531)$. Data were consistent with the geometrical dimensions of the cells (length $94.2 \pm 1.89 \mu \mathrm{m}$, width $17.9 \pm 0.42 \mu \mathrm{m}, n=126$ ).

3 When hyperpolarizing to $-120 \mathrm{mV}$ from a holding potential of $-40 \mathrm{mV}, 252$ of 306 tested cells

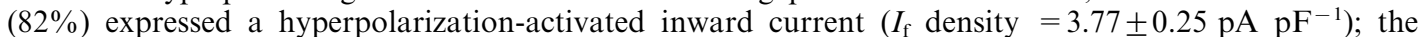
current was considered to be present in a given cell if its density at $-120 \mathrm{mV}$ was larger than $0.5 \mathrm{pA}$ $\mathrm{pF}^{-1}$.

4 Current activation was sigmoidal and fitted a Boltzmann model; the average activation curve $(n=25)$ showed a maximum current amplitude of $205.97 \pm 19.94 \mathrm{pA}$, corresponding to $3.87 \pm 0.63 \mathrm{pA} \mathrm{pF}^{-1}$, voltage of half-maximal activation $\left(\mathrm{V}_{1 / 2}\right)$ at $-86.68 \pm 2.19 \mathrm{mV}$ and a slope of $-11.39 \pm 0.69 \mathrm{mV}$. The reversal potential of $I_{\mathrm{f}}$ measured by tail-current analysis was $-13.07 \pm 1.92 \mathrm{mV}(n=6)$. The addition of $\mathrm{CsCl}(5 \mathrm{~mm})$ fully and reversibly blocked the current.

5 In the presence of the $\beta$-adrenoceptor agonist isoprenaline (Iso, $1 \mu \mathrm{M}$ ), $\mathrm{V}_{1 / 2}$ was significantly shifted toward less negative potentials by $6.06 \pm 1.96 \mathrm{mV}(n=16, P=0.0039)$. The selective $\mathrm{A}_{1}$-adenosine receptor agonist cyclopentyladenosine $(\mathrm{CPA}, 1 \mu \mathrm{M})$ caused a statistically significant shift of $\mathrm{V}_{1 / 2}$ toward more negative potentials with respect to the control curve, both in the absence $(-7.37 \pm 1.83 \mathrm{mV}$, $P=0.0005, n=11)$ and in the presence of $1 \mu \mathrm{M}$ Iso $(-4.97 \pm 1.78, P=0.031, n=6)$.

6 These results demonstrate that a current with the properties of $I_{\mathrm{f}}$ described in cardiac primary and secondary pacemakers occurs in the majority of human atrial cells. While the pathophysiological relevance of $I_{\mathrm{f}}$ in human atrial tissue remains to be defined, our data clearly show that it is modulated through stimulation of $\beta$-adrenoceptors and $\mathrm{A}_{1}$-adenosine receptors.

Keywords: Human atrial myocytes; pacemaker current; adenosine; isoprenaline

\section{Introduction}

The hyperpolarization-activated inward current $I_{\mathrm{f}}$ is thought to play a role in pacemaking in both primary and secondary pacemakers (Di Francesco, 1981a, b; 1991). This current is both barium-insensitive and caesium-sensitive; in the sinus node, it is modulated by $\beta$-adrenoceptor stimulation, acetylcholine and adenosine (Di Francesco \& Tromba, 1988; Di Francesco, 1995; Zaza et al., 1996). The existence of $I_{\mathrm{f}}$ in the human myocardium (atrial trabeculae) was demonstrated for the first time by Carmeliet (1984). A current with the characteristics of $I_{\mathrm{f}}$ was described in human isolated atrial myocytes (Heidbüchel et al., 1987; Thuringer et al., 1992). Thuringer et al. showed that $I_{\mathrm{f}}$ varied greatly in amplitude from cell to cell and that the activation voltage in most cells was approximately $-65 \mathrm{mV}$. It has been speculated that $I_{\mathrm{f}}$ could play a role in causing ectopic atrial automaticity (Carmeliet, 1984; Thuringer et al., 1992).

The presence of $I_{\mathrm{f}}$ in other cardiac non-pacemaking cells (i.e. ventricular myocytes) has recently been demonstrated ( $\mathrm{Yu}$ et al., 1993; 1995; Cerbai et al., 1994b; 1996). Some of us also recently demonstrated that $I_{\mathrm{f}}$ amplitude in rat ventricular myocytes is related to the severity of cardiac hypertrophy (Cerbai et al., 1996), becoming even larger in failing hearts

\footnotetext{
${ }^{1}$ Author for correspondence at: Department of Pharmacology, Viale GB Morgagni 65, 50134 Firenze, Italy.
}

(Cerbai et al., 1995). Furthermore, $I_{\mathrm{f}}$ is consistently present in myocytes isolated from human failing hearts (Cerbai et al., 1997), where its amplitude is modulated by $\beta$-adrenoceptor stimulation. These data suggest that $I_{\mathrm{f}}$ may represent an important arrhythmogenic factor in heart failure (Cerbai et al., 1997).

Normally polarized human atrial specimens may exhibit a diastolic depolarization phase (Bush et al., 1971; Escande et al., 1986; Singer, 1990), which has been implicated in initiating atrial arrhythmias (Bush et al., 1971). Consequently, we thought that it would be important to have more information on the characteristics of $I_{\mathrm{f}}$ in human atrial myocytes, on its incidence, i.e. what percentage of myocytes show $I_{\mathrm{f}}$, and on its modulation in order to gain insight into its possible functional role.

\section{Methods}

\section{Cell isolation and storage}

Small samples from human right atrial appendages were used to isolate single myocytes. The specimens, obtained from tissue that it routinely excised from the heart of patients undergoing coronary bypass surgery during the preparation of extra-corporeal circulation, were brought to the laboratory in cold 'transport saline' (see Solutions). The tissue was cut into small 
blocks $\left(1 \mathrm{~mm}^{3}\right)$ which were then disaggregated in a tissue dissociation vessel (Jacobson et al., 1990; Pelzmann et al., 1995). The dissociation procedure started with a pre-digestion step (lasting about $7 \mathrm{~min}$ ) in the 'isolation solution' containing $0.25 \%$ trypsin (Sigma, Deisenhofen, Germany). After this step was completed, the solution was replaced by an isolation solution containing $300 \mathrm{iu} \mathrm{ml}^{-1}$ collagenase (Sigma, type Ia). The solution in the isolation vessel was replaced with fresh collagenase solution every $15 \mathrm{~min}$ and the progress of dissociation was followed at each step by microscopic examination of the collected medium. Starting from the fourth change, the

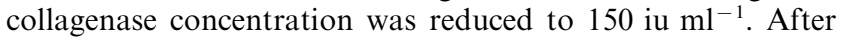
isolation, the cells were carefully exposed to normal $(1 \mathrm{mM})$ calcium ion concentrations $\left(\left[\mathrm{Ca}^{2+}\right]\right)$ by washing them a few times with isolation solution in which the $\left[\mathrm{Ca}^{2+}\right]$ was raised stepwise $(50,100,200,500 \mu \mathrm{M})$. Approximately 50 to 100 intact myocytes per preparation were normally obtained by this method. The isolated cells were either kept at room temperature and used within the day, or alternatively stored for $3-$ $20 \mathrm{~h}$ in a tissue culture incubator at $37^{\circ} \mathrm{C}$ in cell culture medium M199 (Sigma) containing penicillin $\left(50 \mathrm{iu} \mathrm{ml} l^{-1}\right)$ and streptomycin $\left(50 \mathrm{mg} \mathrm{ml}^{-1}\right)$.

\section{Patients}

Tissue specimens were obtained from 70 patients of either sex (age: $63.4 \pm 11.7$ years, mean \pm s.d.) undergoing cardiac surgery; $90 \%$ of the interventions were revascularizations. All patients were under treatment with various combinations of drugs, including Ca-antagonists, acetylsalicylic acid and nitrate compounds. Cells from four patients who had been previously treated with $\beta$-adrenoceptor blockers were not used for experiments in which drug effects were tested.

All patients gave their informed consent for use of their tissue samples. The use of human tissue was also approved by the local ethical committees.

\section{Electrophysiological recordings}

The patch-clamp technique (whole cell recording) was used to measure electrophysiological properties of the human isolated atrial myocytes. Cells were placed in an experimental bath on the platform of an inverted microscope (Zeiss Axiovert 135, Germany; Nikon Diaphot TMD, Japan). Experiments were performed with a patch amplifier (Axopatch-1B, Axon Instruments, CA, U.S.A.; List EPC-7, List, Darmstadt, Germany) interfaced to a personal computer (based on Intel 80486 processor) by means of a general purpose DAC/ADC interface (Labmaster Tekmar, Scientific Solutions). Data were viewed on-line on an analogic oscilloscope and on a computer screen. Experimental control, data acquisition and preliminary analysis were performed by means of the integrated software package pClamp (Axon Instruments, CA, U.S.A.). Cells were superfused with normal Tyrode solution (NT, see Solutions) or with a modified Tyrode solution (TIF) during measurements of the hyperpolarization-activated inward current $\left(I_{\mathrm{f}}\right)$. Temperature was maintained in the range of $36-37^{\circ} \mathrm{C}$. Patch-clamp pipettes were prepared from glass capillary tubes (Garner Glass Co., CA, U.S.A.) by means of a two-stage vertical puller (Hans Otchoski, Homburg, Germany) and fire-polished just before use. Pipettes had a resistance of 1.5-2.5 $\mathrm{M} \Omega$ when filled with the internal solution (see Solutions).

For most of the experiments with drug application, the patch-clamped cell was superfused by means of a temperaturecontrolled micro-superfusor which allowed rapid changes to the solution bathing the cell; this enabled us to minimize current run-down and to reduce exposure of the other cells present in the experimental chamber to drugs. However, the relatively short duration of the cell under the recording conditions did not allow for a complete dose-dependent determination of the drug effect. Preliminary experiments were performed to determine those concentrations that gave maximal effects.
Isoprenaline was dissolved in distilled water to get a stock solution with a final concentration of $10 \mathrm{mM}$. The stock solution, which contained ascorbic acid $\left(1 \mathrm{mg} \mathrm{m}^{-1}\right)$ as an antioxidant, was then diluted with Tyrode solution to get the final isoprenaline concentration.

Cyclopentyladenosine (CPA), a selective $\mathrm{A}_{1}$-adenosine receptor agonist (Moos et al., 1985), was dissolved in 50\% ethanol to prepare a stock solution of $1 \mathrm{~mm}$, which was then diluted with Tyrode solution to the final concentration.

\section{Solutions}

The composition of the solutions employed was as follows (in $\mathrm{mM}$ ): transport saline: $\mathrm{NaCl} 27, \mathrm{KCl} 20, \mathrm{MgCl}_{2} 1.5$, (+)-glucose 274, HEPES 5, adjusted to $\mathrm{pH} 7.0$ with $\mathrm{NaOH}$. Isolation solution: $\mathrm{NaCl} 120, \mathrm{KCl} 10, \mathrm{KH}_{2} \mathrm{PO}_{4} 1.2, \mathrm{MgCl}_{2}$ 1.2, (+)glucose 10, HEPES-NaOH $10(\mathrm{pH} 7.0)$ and taurine 20. Normal Tyrode solution (NT): $\mathrm{NaCl} 140, \mathrm{KCl} 5.4, \mathrm{CaCl}_{2} 1, \mathrm{MgCl}_{2} 1.2$, HEPES-NaOH (pH 7.35) 5 and glucose, 10. Modified Tyrode solution for hyperpolarization-activated inward current measurements (TIF): $\mathrm{NaCl} 140, \mathrm{KCl} 25, \mathrm{CaCl}_{2} 1, \mathrm{MgCl}_{2} 1.2$, HEPES-NaOH (pH 7.35) 5, glucose $10, \mathrm{BaCl}_{2} 1, \mathrm{MnCl}_{2} 2$ and 4 -aminopyridine 0.5 ; this solution allowed for the reduction of interference from other currents, i.e., L-type calcium current $\left(I_{\mathrm{Ca}, \mathrm{L}}\right)$, inward rectifier-like current $\left(I_{\mathrm{K}_{1}}\right)$ and transient outward potassium current $\left(I_{\mathrm{to}}\right)$. Internal solution (used to fill the patch micro-pipettes): $\mathrm{KCl} 110, \mathrm{ATP} / \mathrm{K}^{+} 4.3, \mathrm{MgCl}_{2} 2, \mathrm{CaCl}_{2} 1$, EGTA 11, HEPES $/ \mathrm{K}^{+} 10$, adjusted to $\mathrm{pH} 7.4$ with $\mathrm{KOH}$ (free $\left.\left[\mathrm{Ca}^{2+}\right]<10^{-8} \mathrm{M}\right)$.

\section{Data analysis and statistics}

Data analysis and fitting were performed by using the programme Origin 2.94 (MicroCal Software Inc., MA, U.S.A.) running on an Intel 80486 microprocessor-based personal computer. For fitting functions, non-linear models of convergence to solutions were used.

To evaluate steady-state values of the hyperpolarizationactivated current, data were fitted to an exponential decay. The difference between the extrapolated value and that of the current at the end of the hyperpolarization step was usually small (in the order of a few pA). Current amplitudes were measured as the difference between the value at the steady state and that at the beginning of the test pulse. A Boltzmann model

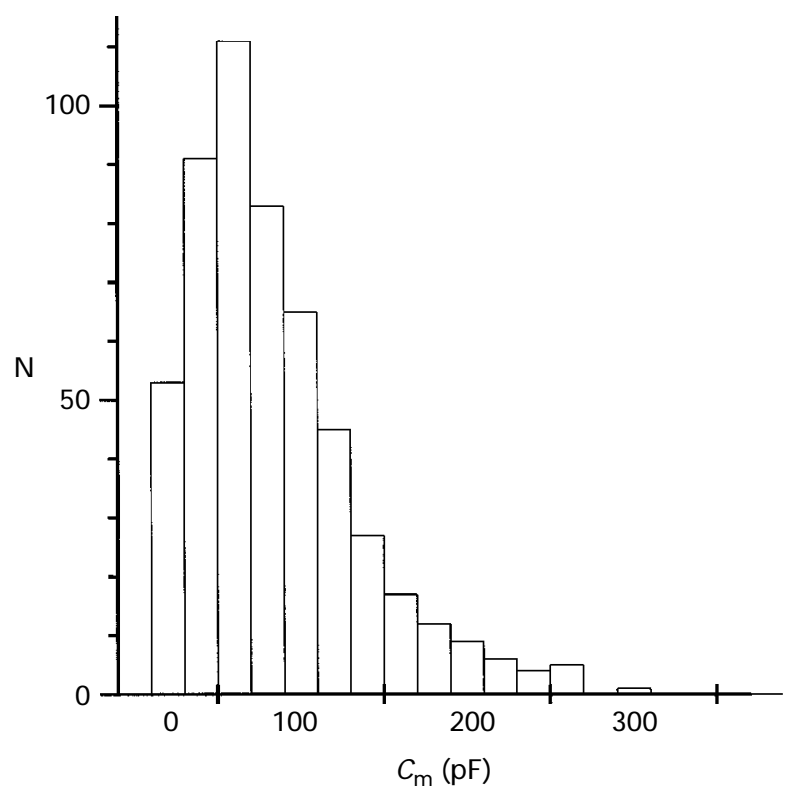

Figure 1 Frequency histogram of cell membrane capacitance $\left(C_{\mathrm{m}}\right.$, in $\mathrm{pF}$ ) as measured with the patch-clamp technique in single myocytes isolated from the human right atrium. Mean \pm s.e.mean of membrane capacitance was $85.06 \pm 2.41(n=531)$. 
based on the partition theorem according to the general equation:

$$
\mathrm{y}=\frac{1}{1+\mathrm{e}^{\left(\mathrm{v}-\mathrm{v}_{1 / 2}\right) / \mathrm{k}}}
$$

was fitted to the activation data, where $\mathrm{V}(\mathrm{mV})$ is the test membrane potential, $\mathrm{V}_{1 / 2}(\mathrm{mV})$ is the fitted potential for halfmaximal activation and $\mathrm{k}(\mathrm{mV})$ is related to the slope of the activation curve.

Cell membrane capacitance $\left(C_{\mathrm{m}}\right)$ was measured by applying a pulse of small amplitude $(\Delta \mathrm{V}=5 \mathrm{mV})$ starting from a holding potential of $-40 \mathrm{mV}$, i.e. close to the linear region of the current-potential relationship of the cell. The current transient following this clamp protocol was fitted with a mono-exponential model to compute series resistance $\left(R_{\mathrm{s}}\right)$ and then $C_{\mathrm{m}}$ by use of the two equations given below:

$$
R_{\mathrm{S}}=\frac{\Delta V}{I_{\text {peak }}}
$$

and

$$
C_{\mathrm{m}}=\frac{\tau}{R_{\mathrm{S}}}
$$

where $I_{\text {peak }}$ is the maximum level of current (relative to the holding current) following the depolarization and $\tau$ is the time constant of the exponential current decay. The membrane capacitance values obtained were used to compute ionic current densities $\left(I_{\mathrm{f}}\right.$ density in $\left.\mathrm{pA} \mathrm{pF}^{-1}\right)$.

To evaluate the reversal potential of $I_{\mathrm{f}}$, a previously described protocol was used (Cerbai et al., 1994b). Briefly, tail currents were recorded by test steps to membrane potentials ranging from $-80 \mathrm{mV}$ to $+20 \mathrm{mV}$, preceded by a conditioning potential step to $-120 \mathrm{mV}$ which activated more than $90 \%$ of the current. To compensate for the presence of interfering currents, the tails were corrected by subtracting currents obtained from an experimental protocol in which the conditioning step was of smaller amplitude (normally $-60 \mathrm{mV}$ ) and not sufficient to activate $I_{\mathrm{f}}$. Tail amplitudes were then plotted versus the test membrane potential to obtain the instantaneous current-voltage relationship.

Given the relatively small number of observations and the nature of the measured data that are likely to be non-normally

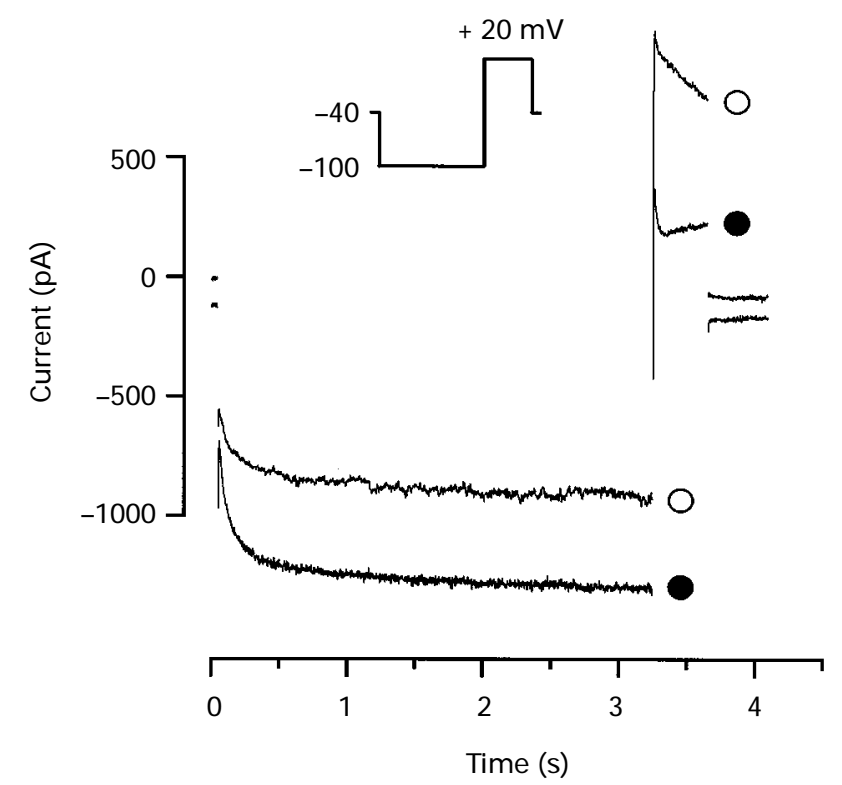

Figure 2 A typical recording of the current measured at $-100 \mathrm{mV}$ in normal Tyrode solution (open symbol) and in a solution modified to ease isolation of $I_{\mathrm{f}}$ from other interfering currents (solid symbol). distributed, non-parametric statistics (Wilcoxon) on paired data (one- or two-tail, according to the need) were used. All results presented as mean \pm s.e.mean, real probability levels and the usual starred notation $(* P<0.05 ; * * P<0.01$; $* * * P<0.001)$.

\section{Results}

\section{$\mathrm{I}_{f}$ characterization}

Cells isolated from the atrial right appendage of human hearts had an average membrane capacitance $\left(C_{\mathrm{m}}\right)$ of $85.06 \pm 2.41 \mathrm{pF}$ $(n=531)$. The distribution histogram was monomodal, skewed to the right (see Figure 1), with median $66.2(\mathrm{pF})$. These data are consistent with the geometrical dimensions of the cells (length $94.2 \pm 1.89 \mu \mathrm{m}$, width $17.9 \pm 0.42 \mu \mathrm{m}, n=126$ ).

Following clamp steps to hyperpolarized membrane potential, a time-dependent inward current $\left(I_{\mathrm{f}}\right)$ was recorded in most of the tested cells. The current was considered to be
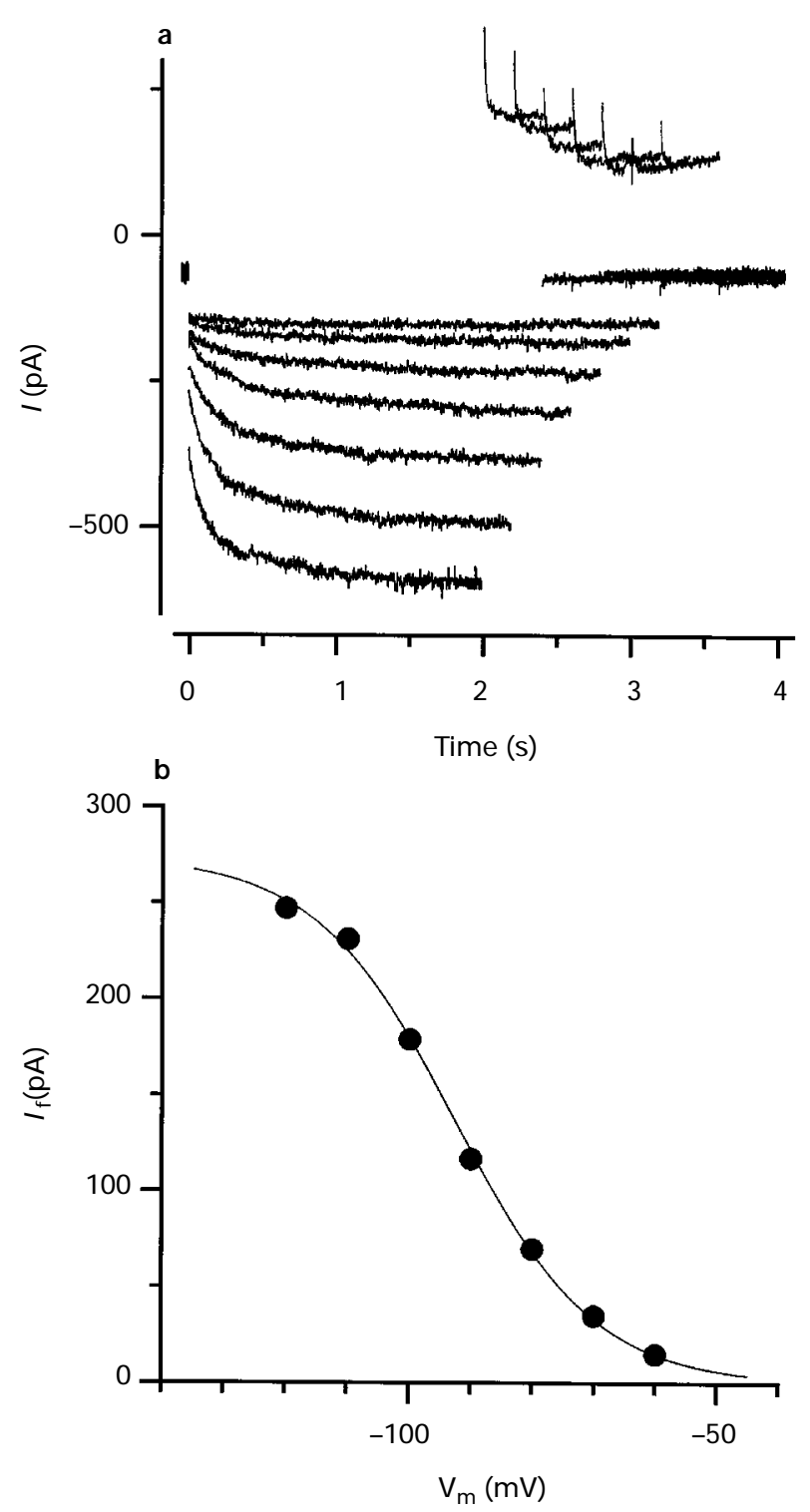

Figure 3 Determination of the activation curve for $I_{\mathrm{f}}$. (a) A representative example of the current traces obtained by hyperpolarizing the cell to a test potential between $-50 \mathrm{mV}$ and $-140 \mathrm{mV}$ in steps of $-10 \mathrm{mV}$. (b) Result of fitting of a Boltzmann model to the experimental data obtained from currents in (a). Each point is the extrapolated steady state current value computed by means of an exponential model. 
- Control

$\mathrm{O} \mathrm{Cs}^{+}$

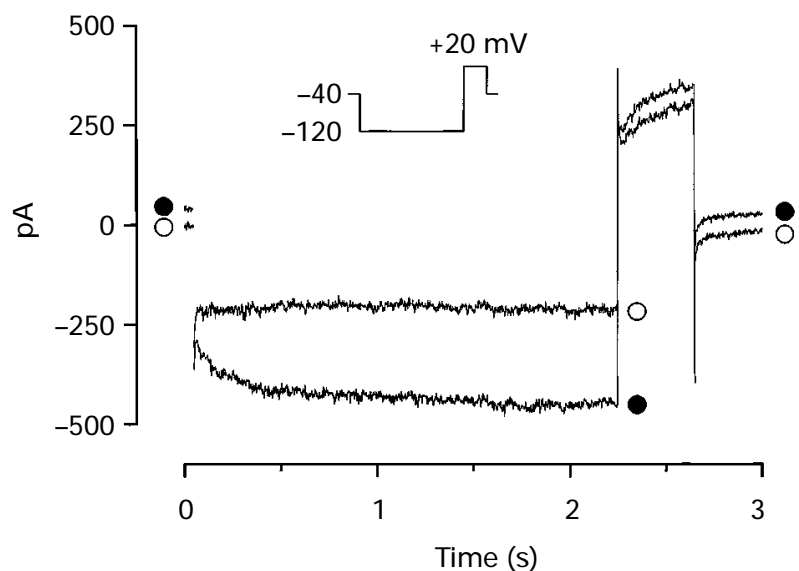

Figure 4 Representative recordings showing the effects of $\mathrm{Cs}^{+}$ (5 mM) containing solution compared to control solution. Caesium ions blocked the inward relaxation of the current recorded following a membrane potential step to $-120 \mathrm{mV}$.
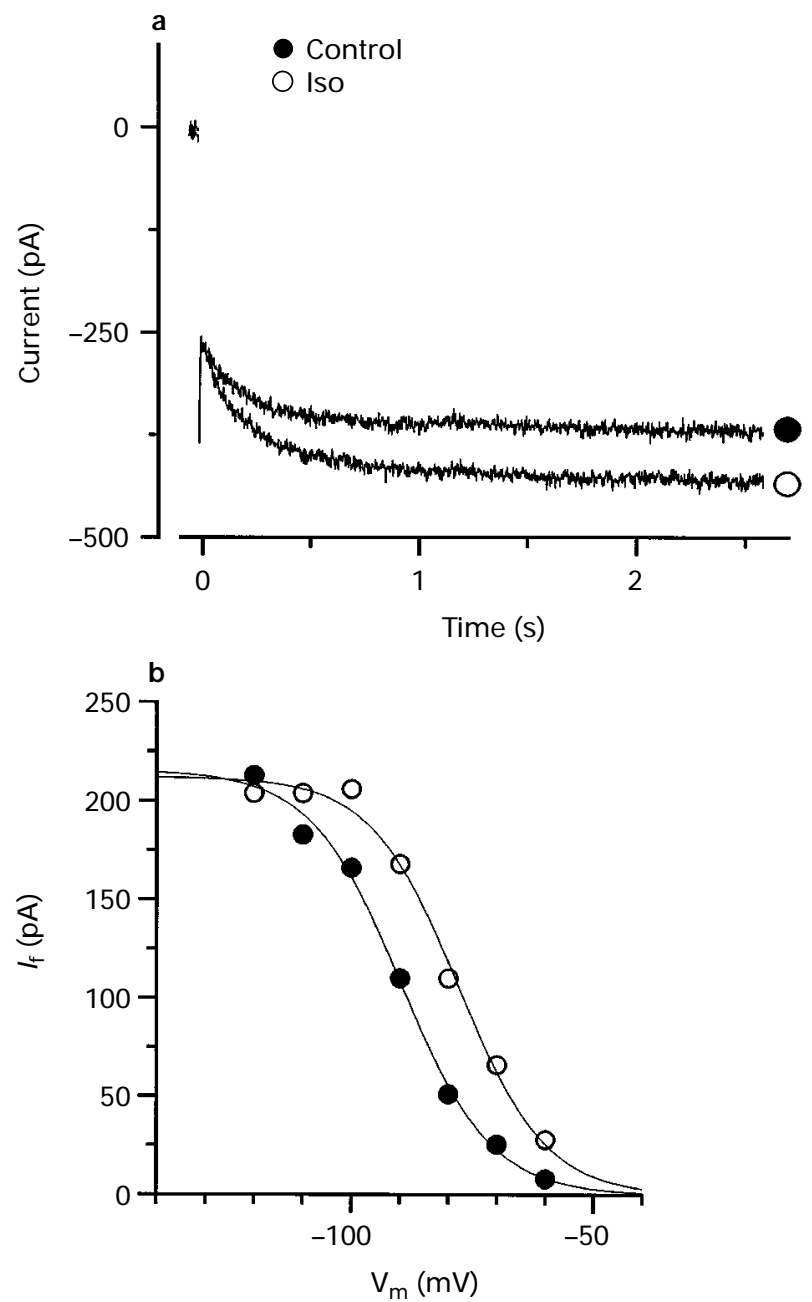

Figure 5 Effect of superfusion with the $\beta$-adrenoceptor agonist isoprenaline $1 \mu \mathrm{M}$ (Iso) on the $I_{\mathrm{f}}$ current compared to control. (a) Traces recorded from a single isolated human atrial myocyte hyperpolarized to $-90 \mathrm{mV}$ from a holding potential of $-40 \mathrm{mV}$. (b) Activation curves of the $I_{\mathrm{f}}$ in control solution and in the presence of iso-prenaline. present in a given cell if its density (see Methods for a definition) was larger than $0.5 \mathrm{pA} \mathrm{pF}^{-1}$ when measured at $-120 \mathrm{mV}$. Using this criterion 252 out of 306 tested cells $(82 \%)$ expressed the hyperpolarization-activated inward cur-

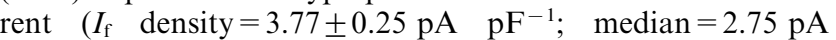
$\left.\mathrm{pF}^{-1}\right)$.

Figure 2 shows a typical example of the $I_{\mathrm{f}}$ recorded from a human atrial myocyte bathed in normal Tyrode solution (NT, $\mathrm{K}^{+} 5.4 \mathrm{~mm}$ ). The current trace shows a clear exponential inward relaxation following a potential step to $-100 \mathrm{mV}$ from a holding potential of $-40 \mathrm{mV}$. When the bathing solution surrounding the cell was changed to the modified Tyrode solution containing a high $(25 \mathrm{~mm})$ potassium ion concentration (TIF), the inward current amplitude at the same membrane potential was clearly increased. All the following measurements were performed in TIF solution to allow for a better separation of $I_{\mathrm{f}}$ from other interfering currents.

Activation of the hyperpolarization-activated inward current $\left(I_{\mathrm{f}}\right)$ is voltage-dependent. This is clearly shown in Figure 3. In Figure 3a, a typical example of the current traces elicited by hyperpolarizing the cell membrane to various test potentials from a holding potential of $-40 \mathrm{mV}$ is presented. Relaxation was exponential, with faster kinetics at more hyperpolarized membrane potentials. In Figure 3b, the steady-state net current
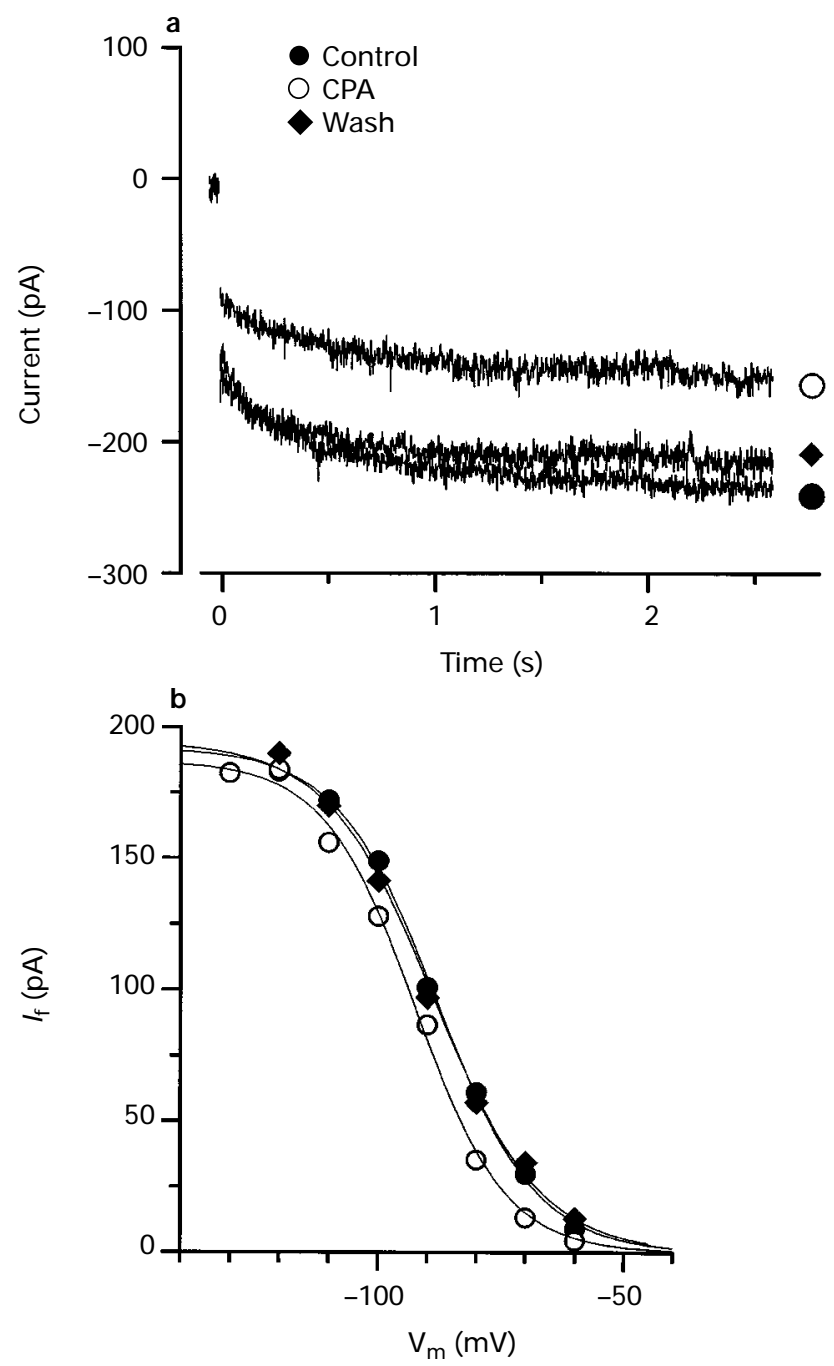

Figure 6 Effect of the superfusion with the $\mathrm{A}_{1}$-adenosine receptor agonist cyclopentyladenosine $1 \mu \mathrm{M}(\mathrm{CPA})$ on the $I_{\mathrm{f}}$ current compared to control. (a) Traces recorded following a membrane potential step to $-90 \mathrm{mV}$ from a holding potential of $-40 \mathrm{mV}$. (b) Activation curves of the $I_{\mathrm{f}}$ in control solution and in the presence of CPA. Traces and experimental data points recorded after washout of CPA are also shown (Wash). 
values are shown versus the test membrane potential. The points were fitted by a Boltzmann model (see Methods). Only cells in which a complete activation curve could be determined and which gave good estimates of all the equation parameters were used for the analysis. With this criterion, an average activation curve was obtained with: $I_{\max } 205.97 \pm 19.94 \mathrm{pA}, \mathrm{V}_{1 / 2}$ $-86.68 \pm 2.19 \mathrm{mV}, \mathrm{k}-11.39 \pm 0.69 \mathrm{mV}(n=25)$. The maximum current density, obtained from the activation curve parameters normalized to cell dimension expressed by the cell membrane capacitance, was $3.87 \pm 0.63 \mathrm{pA} \mathrm{pF}^{-1}(n=25)$.

The reversal potential $\left(\mathrm{E}_{\text {rev }}\right)$ of $I_{\mathrm{f}}$ current was measured by using tail current analysis (data not shown). When the tail current amplitudes were plotted versus the test membrane potentials, an instantaneous current-potential relationship was obtained which could be fitted with a linear model. The above analysis gave a value for $\mathrm{E}_{\mathrm{rev}}$ of $-13.07 \pm 1.92 \mathrm{mV}(n=6)$.

$I_{\mathrm{f}}$ current was efficiently and reversibly blocked by caesium ions added to the bathing solution. Figure 4 shows a typical recording of this effect. As can be clearly seen, the time dependent inward current was completely abolished by superfusing the cell with TIF-solution containing caesium ions $\left(\mathrm{Cs}^{+}\right)$at a concentration of $5 \mathrm{~mm}$. The blocking action of $\mathrm{Cs}^{+}$ was consistently observed in all of the cells tested; the block was considered to be effective if no time-dependent inward current was left. The block by $\mathrm{Cs}^{+}$was removed by washout (data not shown) but the signal to noise ratio of the current was often worse than in control conditions. As shown in the figure, $\mathrm{Cs}^{+}$inconsistently blocked a time-independent inward current; this could be due to the effect on a residual potassium current not completely blocked by barium, due to the high variability of $I_{\mathrm{K} 1}$ in human atrial myocytes (Van Wagoner et al., 1997).

\section{Pharmacological modulation of $\mathrm{I}_{f}$}

Figure 5a shows a representative recording of the effect of the $\beta$-adrenoceptor agonist isoprenaline (Iso) at a concentration of $1 \mu \mathrm{M}$ on $I_{\mathrm{f}}$ measured at $-90 \mathrm{mV}$. It is apparent that in the presence of Iso, current amplitude is increased. Iso shifted in a

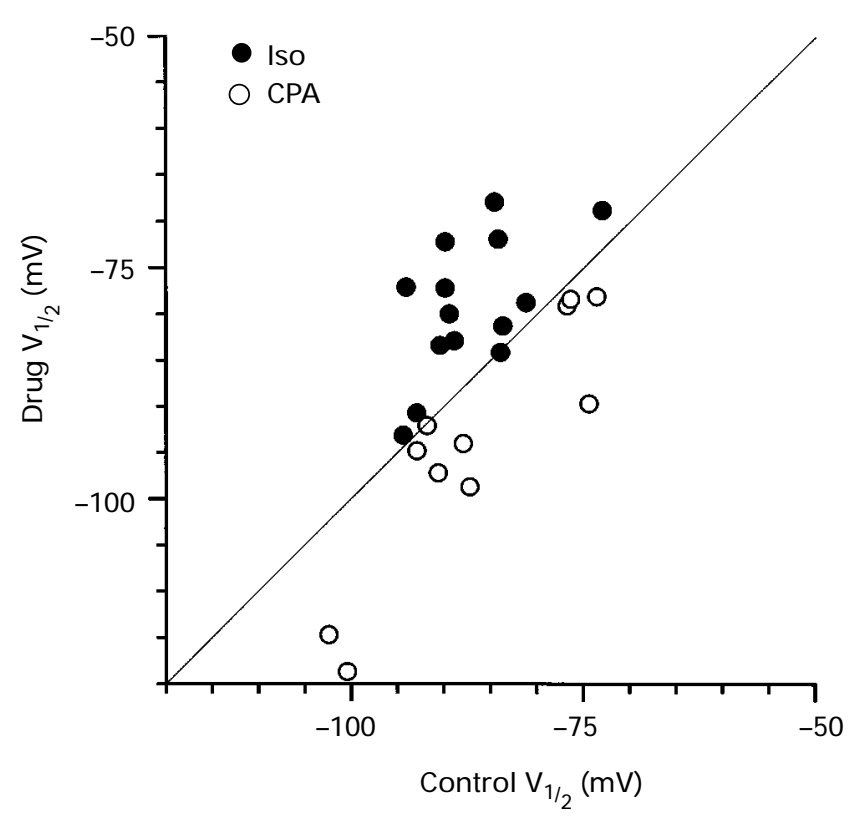

Figure 7 Summary of the changes caused by isoprenaline (Iso) and cyclopentyladenosine (CPA) on the half maximal activation potential $\left(\mathrm{V}_{1 / 2}\right)$ of the activation curve of $I_{\mathrm{f}}$. Each point represents a cell; abscissae and ordinates are the $\mathrm{V}_{1 / 2}$ values in control and after drug, respectively. The line crossing the graph (slope $=1$ ) represents the $\mathrm{H}_{\mathrm{o}}$ hypothesis (no effect). Points falling above the $\mathrm{H}_{\mathrm{o}}$ line represent activation curves shifted to less polarized potentials; those below the $\mathrm{H}_{\mathrm{o}}$ line refer to activation curves shifted to more polarized potentials. statistically significant $(P=0.0039, * *)$ manner the half activation potential $\left(\Delta \mathrm{V}_{1 / 2}\right)$ of the activation curve toward a less negative potential (Figure $5 \mathrm{~b}$ ). The average shift was $6.06 \pm 1.96 \mathrm{mV}(n=16) . I_{\max }$ and slope were not modified.

In Figure 6 an example of the action of the $A_{1}$-adenosine receptor agonist cyclopentyladenosine (CPA) on $I_{\mathrm{f}}$ is shown. Figure 6a shows that the current amplitude measured at $-90 \mathrm{mV}$ was decreased when the cell was superfused with CPA at a concentration of $1 \mu \mathrm{M}$. The effect of CPA was reversed by washout. The activation curve of $I_{\mathrm{f}}$ is shifted toward more negative potentials without any effect on the steepness of the current to potential relationship. Statistical analysis proved that CPA caused a statistically significant shift of the half maximal activation potential toward more negative potentials (Figure 6b). The average shift was $-7.37 \pm 1.83 \mathrm{mV}$, $P=0.0005 * * *(n=11)$.

Figure 7 presents the individual changes of the half activation potential $\left(\mathrm{V}_{1 / 2}\right)$ of $I_{\mathrm{f}}$ caused by Iso and CPA. Each cell is represented by a point the abscissa and ordinate of which are the $V_{1 / 2}$ values in control and after drug, respectively. The line (slope $=1$ ) crossing the graph represents the $\mathrm{H}_{0}$ hypothesis (no
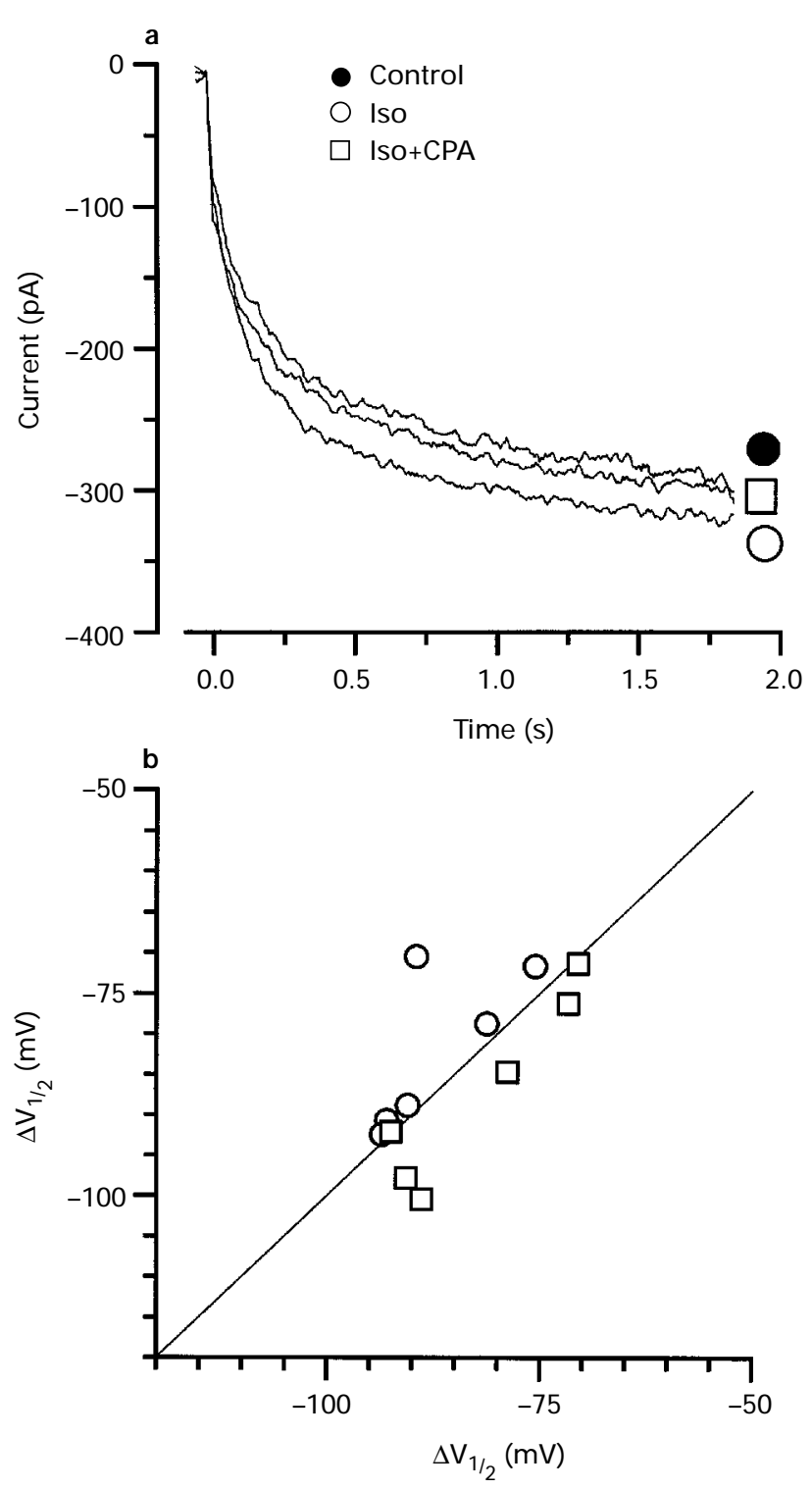

Figure 8 Effect of cyclopentyladenosine (CPA) on $I_{\mathrm{f}}$ in the presence of isoprenaline (Iso). The positive shift of $\mathrm{V}_{1 / 2}$ of the activation curve of $I_{\mathrm{f}}$ caused by Iso was reversed by CPA addition. (a) $I_{\mathrm{f}}$ traces recorded at $-90 \mathrm{mV}$ from a holding potential of $-40 \mathrm{mV}$ superimposed. (b) Summary of the results obtained in 6 cells by use of the same format as shown in Figure 7. 
effect). Negative (CPA) and positive (Iso) $\mathrm{V}_{1 / 2}$-shifts are represented by points lying below and above the $\mathrm{H}_{0}$ line, respectively.

Figure 8a shows an example of the action that CPA exerts in the presence of Iso. Current traces recorded on hyperpolarization to $-90 \mathrm{mV}$ from a holding potential of $-40 \mathrm{mV}$ are superimposed. Adding CPA $(1 \mu \mathrm{M})$ to the superfusing solution reversed the positive shift of $\mathrm{V}_{1 / 2}$ on the activation curve of $I_{\mathrm{f}}$ caused by Iso $(1 \mu \mathrm{M})$. The analysis showed that this effect was statistically significant; superfusion with Iso caused a positive shift $\left(\Delta \mathrm{V}_{1 / 2} 5.03 \pm 2.81(\mathrm{mV})\right.$, $P=0.016^{*}, n=6$ ) which was antagonized by the negative shift caused by CPA $\left(\Delta \mathrm{V}_{1 / 2}-4.97 \pm 1.78, P=0.031^{*}, n=6\right)$. In Figure $8 b$, the same format as shown in Figure 7 is used to summarize these data.

\section{Discussion}

The present results demonstrate that a current having the electrophysiological characteristics of the pacemaker current $I_{\mathrm{f}}$ is present in more than $80 \%$ of atrial myocytes isolated from atrial appendages of patients undergoing cardiac surgery. All the patients were on sinus rhythm at the time of surgery, which was generally performed for ventricular revascularization. We considered $I_{\mathrm{f}}$ to be present when its density was larger than $0.5 \mathrm{pA} \mathrm{pF}^{-1}$ after a hyperpolarizing step to $-120 \mathrm{mV}$. Halfactivation voltage was approximately $-86 \mathrm{mV}$, which does not support a functional role for this current under physiological conditions in human atrial myocytes. In fact, the maximum diastolic potential in human atrial myocytes has been shown to be generally below this value (i.e., $-70 /-75 \mathrm{mV}$ ) (Bush et al., 1971; Gelband et al., 1972; Ten Eick \& Singer, 1979; Escande et al., 1985; Singer, 1990; Wang et al., 1993) implying that the current undergoes little, if any, activation. However, the presence of $I_{\mathrm{f}}$ in such a high percentage of atrial myocytes deserves further investigation. It is possible that a shift of the activation voltage toward more negative values could represent a mechanism for avoiding pacemaking of atrial cells, as suggested for ventricular myocytes by Yu et al. (1993; 1995). Similar to the observed effects of hypertrophy or failure on other ionic currents (Beuckelmann et al., 1993; Nuss \& Houser, 1993; Cerbai et al., 1994a,b; 1996; 1997), the properties of $I_{\mathrm{f}}$ could be modulated by disease, in such a way that it may play a role in pathological conditions. However, regardless of the physiopathological significance of the presence of $I_{\mathrm{f}}$ in human atrial myocytes, the most important and original finding of this work is the demonstration of $I_{\mathrm{f}}$ modulation by $\beta$-adrenoceptor and $\mathrm{A}_{1}$-adenosine receptor stimulation in human myocytes. As shown in other cells expressing $I_{\mathrm{f}}, \beta$-adrenoceptor stimulation increases $I_{\mathrm{f}}$ by shifting the voltage of activation toward more positive values (Earm et al., 1983; Di Francesco, 1995; Cerbai et al., 1996). Thus the effect of $\beta$ adrenoceptor stimulation on $I_{\mathrm{f}}$ appears to be generally valid.

The effect of adenosine receptor stimulation requires further comment. Adenosine, acting on $\mathrm{A}_{1}$ receptor subtypes, influences ionic currents of atrial myocytes. Previous evidence suggests that the direct effect of adenosine on atrial cells is due to the activation of a $\mathrm{K}^{+}$conductance leading to membrane hyperpolarization (Belardinelli \& Isenberg, 1983; Kurachi et al., 1986). The same action was considered to be the basis for the negative chronotropic effect of adenosine on sinus node, since $I_{\mathrm{f}}$ was shown to be insensitive to adenosine (Belardinelli et al., 1988). Our data demonstrate that stimulation of $\mathrm{A}_{1^{-}}$ adenosine receptors by CPA shifts the activation curve of $I_{\mathrm{f}}$ toward more negative values, in agreement with recent results by Zaza et al. (1996). They showed that submicromolar concentrations of adenosine directly inhibit $I_{\mathrm{f}}$ and slow pacemaking in rabbit sinoatrial myocytes. If $I_{\mathrm{f}}$, as is likely, is present in human sinoatrial myocytes, it is fair to assume that adenosine will exert the same effects that we observed on $I_{\mathrm{f}}$ in atrial myocytes, i.e. a shift of its activation curve.

As during $\beta$-adrenoceptor stimulation, the effect of $\mathrm{A}_{1^{-}}$ adenosine receptor stimulation on $I_{\mathrm{f}}$ is observed under basal conditions, suggesting that adenosine certainly exerts an effect on human atria. The molecular mechanism of this effect remains to be studied. The possibility that the effect of adenosine on $I_{\mathrm{f}}$ occurs at the same concentration at which it affects $I_{\mathrm{K} \text {,Ado }}$ remains to be assessed; if this is the case, adenosine would at the same time activate and inhibit $I_{\mathrm{f}}$ by hyperpolarizing the cell and by shifting the activation voltage, respectively. The relative contribution of the effects of adenosine should be explored, but it is worth noting that adenosine in vivo does not markedly change the basal heart rate (Wesley \& Belardinelli, 1989; Sidi et al., 1994).

This work has been carried out under the auspices of the Protocol of Technical and Scientific Co-operation between Austria and Italy. We are grateful to the teams of Cardiovascular Surgery of the University of Graz and of the Azienda Ospedaliera Careggi in Firenze. This work was supported by grants from the University of Firenze (MURST 60\% - 1996) and the Austrian Science Foundation P11131-MED and SFB 007.

\section{References}

BELARDINELLI, L., GILES, W.R. \& WEST, A. (1988). Ionic mechanism of adenosine actions in pacemaker cells from rabbit heart. J. Physiol., 405, 615-633.

BELARDINELLI, L. \& ISENBERG, G. (1983). Isolated atrial myocytes: adenosine and acetylcholine increase potassium conductance. Am. J. Physiol., 224, H734-H737.

BEUCKELMANN, D.J., NÄBAUER, M. \& ERDMANN, E. (1993). Alterations of $\mathrm{K}^{+}$currents in isolated human ventricular myocytes from patients with terminal heart failure. Circ. Res., 73, $379-385$.

BUSH, H.L., GELBAND, H., HOFFMAN, B.F. \& MALM, J.R. (1971). Electrophysiological basis for supraventricular arrhythmias. Arch. Surg., 103, 620-624.

CARMELIET, E. (1984). Existence of pacemaker current $\mathrm{I}_{\mathrm{f}}$ in human atrial appendage fibres. J. Physiol., 357, $125 \mathrm{P}$.

CERBAI, E., BARBIERI, M., LI, Q. \& MUGELLI, A. (1994a). Ionic basis of action potential prolongation in hypertrophied myocytes isolated from the heart of hypertensive rats of different ages. Cardiovasc. Res., 28, $1180-1187$.

CERBAI, E., BARBIERI, M. \& MUGELLI, A. (1994b). Characterization of the hyperpolarization-activated current, $I_{f}$, in ventricular myocytes isolated from hypertensive rats. J. Physiol., 481, 58591.

CERBAI, E., BARBIERI, M. \& MUGELLI, A. (1996). Occurrence and properties of the hyperpolarization-activated current, $I_{f}$, in ventricular myocytes from normotensive and hypertensive rats during aging. Circulation, 94, 1674-1681.

CERbAi, E., BARbieri, M., PORCIATti, F. \& MUGelli, A. (1995). Ionic channels in hypertrophy and heart failure: relevance for arrhythmogenesis. New Trends Arrhythmias, 9, 135-139.

CERBAi, E., PINO, R., PORCIATTI, F., SANi, G., TOSCANO, M., MACCHERINI, M., GIUNTI, G. \& MUGELlI, A. (1997). Characterization of the hyperpolarization-activated current, $\mathrm{I}_{\mathrm{f}}$, in ventricular myocytes from human failing heart. Circulation, 95, $568-571$.

DI FRANCESCO, D. (1981a). A new interpretation of the pacemaker current in calf Purkinje fibres. J. Physiol., 314, 359-376.

DI FRANCESCO, D. (1981b). A study of the ionic nature of the pacemaker current in calf Purkinje fibres. J. Physiol., 314, $377-$ 393.

DI FRANCESCO, D. (1991). The contribution of the "pacemaker" current $\left(\mathrm{i}_{\mathrm{f}}\right)$ to generation of spontaneous activity in rabbit sinoatrial node myocytes. J. Physiol., 434, $23-40$.

DI FRANCESCO, D. (1995). The onset and autonomic regulation of cardiac pacemaker activity: relevance of the f current. Cardiovasc. Res., 29, $449-456$. 
DI FRANCESCO, D. \& TROMBA, C. (1988). Inhibition of the hyperpolarization-activated current $\left(\mathrm{i}_{\mathrm{f}}\right)$ induced by acetylcholine in rabbit sino-atrial node myocytes. J. Physiol., 405, 477-491.

EARM, Y.E., SHIMONI, Y. \& SPINDLER, A.J. (1983). A pace-makerlike current in the sheep atrium and its modulation by catecholamines. J. Physiol., 342, 569-590.

ESCANDE, D., CORABOEUF, E., PLANCHE, C. \& LACOUR-GAYET, F. (1986). Effects of the potassium conductance inhibitors on spontaneous diastolic depolarization and abnormal automaticity in human atrial fibers. Basic Res. Cardiol., 81, 244-257.

ESCANDE, D., LOISANCE, D., PLANCHE, C.\& CORABOEUF, E. (1985). Age-related changes of action potential plateau shape in isolated human atrial fibers. Am. J. Physiol., 249, H843- H850.

GELBAND, H., BUSH, H.L., ROSEN, M.R., MYERBURG, R.J. \& HOFFMAN, B.F. (1972). Electrophysiologic properties of isolated preparations of human atrial myocardium. Circ. Res., 30, $293-$ 300

HEIDBÜCHEL, H., VEREECKE, J. \& CARMELIET, E. (1987). The electrophysiological effects of acetylcholine in single human atrial cells. J. Mol. Cell. Cardiol., 19, 1207-1219.

JACOBSON, S.L., ALTSCHULD, R.A. \& HOHL, H. (1990). Muscle cell cultures from human heart. In Cell Culture Techniques in Heart and Vessel Research. ed Piper, H.M. pp. 75-98. Berlin, Heidelberg, New York: Springer.

KURACHI, Y., NAKAJIMA, T. \& SUGIMOTO, T. (1986). On the mechanism of activation of muscarinic $\mathrm{K}^{+}$channels by adenosine in isolated atrial cells: involvement of GTP-binding proteins. Pflügers Arch., 407, 264-274.

MOOS, W.H., SZOTEK, D.S. \& BRUNS, R.F. (1985). N6-Cycloalkyladenosines: potent, $\mathrm{A}_{1}$-selective adenosine agonists. J. Med. Chem., 28, $1383-1384$.

NUSS, H.B. \& HOUSER, S.R. (1993). T-type $\mathrm{Ca}^{2+}$ current is expressed in hypertrophied adult feline left ventricular myocytes. Circ. Res., 73, 777-782.

PELZMANN, B., SCHAFFER, P., MÄCHLER, H., RIGLER, B. \& KOIDL, B. (1995). Adenosine inhibits the L-type calcium current in human atrial myocytes. Naunyn-Schmiedberg's Arch. Pharmacol., 351, $293-297$.
SIDI, A., WESLEY, R.C., BARRETT, R., RUSH, W. \& BERLARDINELLI, L. (1994). Cardiovascular effects of non-xanthine-selective antagonists of $A_{1}$ adenosine receptor in anesthetized pig: pharmacological and therapeutic implications. Cardiovasc. Res., 28, 621-628.

SINGER, D.H. (1990). Automaticity in human cardiac tissue. In Cardiac Electrophysiology: A Textbook. ed. Rosen, M.R., Janse, M.J. \& Wit, A.L. pp. 247-263. Mount Kisco, NY: Futura Publishing Company, Inc.

TEN EICK, R.E. \& SINGER, D.H. (1979). Electrophysiological properties of diseased human atrium. I. Low diastolic potential and altered cellular response to potassium. Circ. Res., 44, 545557.

THURINGER, D., LAURIBE, P. \& ESCANDE, D. (1992). A hyperpolarization-activated current in human myocardial cells. J. Mol. Cell. Cardiol., 24, 451-455.

VAN WAGONER, D.R., POND, A.L., MCCARTHY, P.M., TRIMMER, J.S. \& NERBONNE, J.M. (1997). Outward $\mathrm{K}^{+}$current densities and Kv1.5 expression are reduced in chronic human atrial fibrillation. Circ. Res., 80, $772-781$.

WANG, Z., FERMINI, B. \& NATTEL, S. (1993). Delayed rectifier outward current and repolarization in human atrial myocytes. Circ. Res., 73, 276-285.

WESLEY, R.C. \& BELARDINELLI, L. (1989). Role of endogenous adenosine in post-defibrillation bradyarrhythmia and hemodynamic depression. Circulation, 80, $128-137$.

YU, H. CHANG, F. \& COHEN, I.S. (1993). Pacemaker current exists in ventricular myocytes. Circ. Res., 72, 232-236.

YU, H., CHANG, F. \& COHEN, I.S. (1995). Pacemaker current $I_{\mathrm{f}}$ in adult canine cardiac ventricular myocytes. J. Physiol., 485, 469483.

ZAZA, A., ROCCHETTI, M. \& DI FRANCESCO, D. (1996). Modulation of the hyperpolarization-activated current $\left(\mathrm{i}_{\mathrm{f}}\right)$ by adenosine in rabbit sinoatrial myocytes. Circulation, 94, 734-741.

(Received February 14, 1997 Revised July 17, 1997 Accepted August 1, 1997) 